\section{'AMAZING ENDEAVOUR' OPENED IN ESSEX}

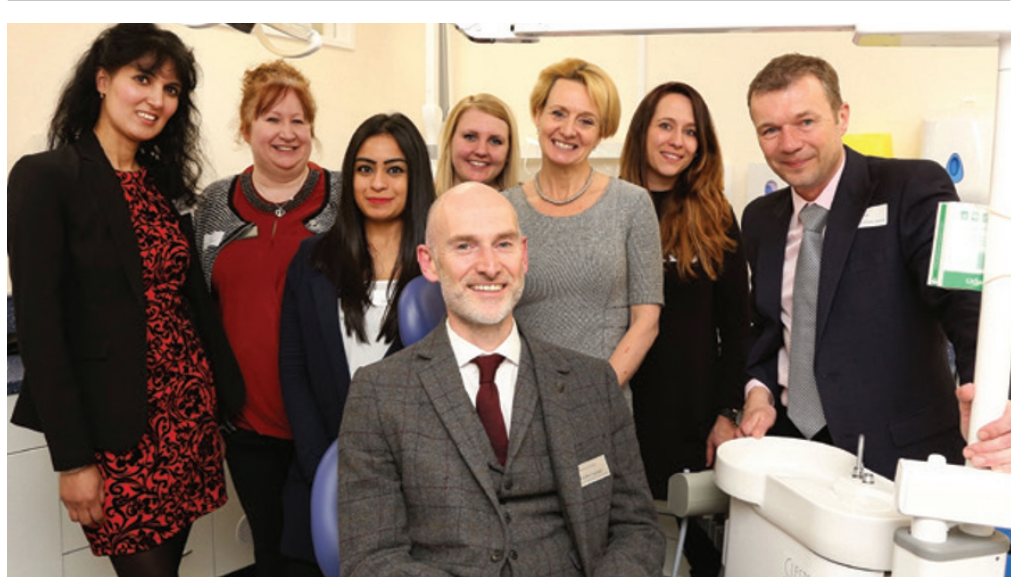

The University of Essex's brand new purpose-built academic dental clinic was officially opened on 26 April 2016 at the Bromley Road Dental Surgery in Colchester. The clinic is already being used to teach and supervise students undertaking patient treatment on the new MSc programmes in Periodontology and Advanced Periodontal Practice.

Six training surgeries are already up and running and by the end of the summer there will also be a state-of-the-art dental skills laboratory in use. This facility is the latest development in the University's growing oral health provision, which is delivered at the University's Colchester and Southend campuses and which already includes the largest dental hygienist and therapist training programme in the UK.

The clinic is one of only a handful of places in the country where advanced periodontology is taught. However, what makes this clinic unique is that it is the only place in England to teach these courses in a non-teaching hospital setting, with students having access to patients in general dental practice surroundings and working in a manner reflective of their everyday working lives.

The new teaching facility is a step towards enhancing the dental treatments available to patients in a primary care setting, which may prove more cost-effective than in a traditional teaching hospital.

During the opening, Sara Hurley, Chief Dental Officer for England, said the 'energy, drive, concept and execution of this endeavour has been amazing' and stressed that the new teaching facility was a step towards 'futureproofing' the dental profession.

\title{
GDC REGISTER WILL DROP REGISTRANTS' ADDRESSES
}

The General Dental Council (GDC) decided in April that it will no longer include full addresses on its public register of dentists and dental care professionals (DCPs). The registration number will be used as the primary method of identification and to confirm professional status.

The decision has been taken following discussions with patients, the profession, the Department of Health and the Professional Standards Authority. There will now be a consultation to decide on whether to publish the name and registration number or the name, the registration number and town of where the dental professional lives.

In addition to this long awaited change, there will be a stronger focus on registrants displaying their registration numbers in workplaces and on paperwork.

The British Dental Association (BDA) welcomed the decision. Chair Mick Armstrong said: 'It is good news that the GDC has made this step in the right direction. The publication of addresses was unnecessary, and out of line with other regulators, as well as a potential risk to registrant safety. The BDA has campaigned long and hard on getting this policy changed:

\section{NATIONAL SMILE MONTH CELEBRATES 40 YEARS}

The 40th anniversary celebration of National Smile Month took place at Kensington Roof Gardens in London on 10 May 2016.

Created by the Oral Health Foundation (formerly the British Dental Health Foundation), National Smile Month is an opportunity for communities to come together and be inspired to help spread positive messages of oral health.

This year's National Smile Month runs from 16 May to 16 June and dental practices and organisations are encouraged to get involved by organising activities and events which will promote oral health within local communities, with a focus on three key messages:

- Brush your teeth last thing at night and at least one other time during the day, with a fluoride toothpaste

- Cut down on how often you have sugary foods and drinks

- Visit your dentist regularly, as often as they recommend.

The Foundation suggest organising a smileathon with the smiley prop (modelled here by $B D J$ staff); a two-minute collective toothbrushing challenge; organising a school visit to deliver oral health education in the classroom; holding a mass brushathon; or organising fundraising events. For more information and inspiration visit www.smilemonth.org/events.

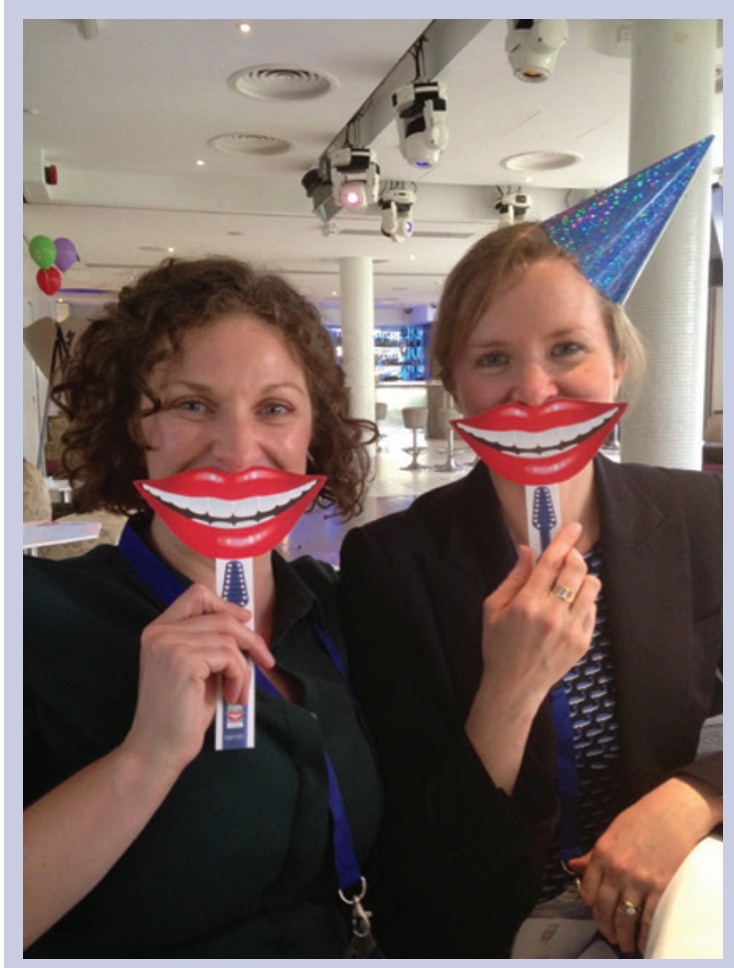

$B D J$ Senior Managing Editor Ruth Doherty (left) and BDJ News Editor Kate Quinlan at the 40 year celebration and launch of National Smile Month 2016 